\title{
The sequential evolution of land tenure norms
}

\author{
Geoff Kushnick $^{\mathrm{a}, *}$, Russell D. Gray b,c, Fiona M. Jordan ${ }^{\mathrm{d}, \mathrm{e}}$ \\ a School of Archaeology and Anthropology, Australian National University, Canberra, Australia \\ b Department of Psychology, The University of Auckland, Auckland, New Zealand \\ c Department of Philosophy, Australian National University, Canberra, Australia \\ d Department of Archaeology and Anthropology, University of Bristol, Bristol, United Kingdom \\ e Evolutionary Processes in Language and Culture, Max Planck Institute for Psycholinguistics, Nijmegen, The Netherlands
}

\section{A R T I C L E I N F O}

\section{Article history:}

Initial receipt 8 April 2013

Final revision received 11 March 2014

\section{Keywords:}

Land tenure

Austronesian

Social evolution

Cultural phylogenetics

Niche construction

\begin{abstract}
A B S T R A C T
Land tenure norms are fundamental to our understanding of the evolution of human cooperation and the emergence of inequality in large-scale societies. A prime example of niche construction, their emergence transformed the selective pressures facing early cultivators. We use phylogenetic methods to reconstruct the evolutionary trajectories of land tenure norms in 97 Austronesian societies. We defined land tenure norms as the primary means by which people use, possess, and redistribute land. Based on existing ethnographic accounts, we coded each society as having one of the following primary land tenure norms: none $(\mathrm{N})$, group $(\mathrm{G})$, kin-group $(\mathrm{K})$, and individual (I). Our analyses of phylogenetic and geographic signal suggest that vertical transmission patterned land tenure norms to a greater degree than horizontal transmission. We assessed the relative strength of plausible models of land tenure evolution using maximum likelihood analyses with lexical and time-scaled trees. Surprisingly, they revealed strong support for a model that allows sequential gains and losses along the pathway N-I-G-K. Our probabilistic reconstruction of ancestral states decisively rejected the claim that Proto-Malayo-Polynesian society was marked by G or K. Our results demonstrate the power of "virtual archaeology" for revealing the dynamics of social evolution.
\end{abstract}

Crown Copyright @ 2014 Published by Elsevier Inc. All rights reserved.

\section{Introduction}

Land tenure norms have long fascinated scholars of human society (de Laveleye, 1874; Engels, 1884; Maine, 1876; Morgan, 1877), as they define the relationship between people and the land, and the rules that regulate how the land can be used, possessed, and redistributed. Centuries of scholarship have painted a relatively clear picture of the diversity of land tenure norms, but a focused account of their evolution has yet to emerge. At the root of the problem is a lack of reliable historical accounts of land tenure transformations. Archaeological data may provide more depth, but it is often difficult to make direct inferences about land tenure norms (Earle, 2000). For these reasons, an alternative approach is necessary.

The bedrock upon which our understanding of the evolution of human cooperation and the transformation to large-scale societies must be grounded, land tenure norms provide a key to understanding other important aspects of human social evolution (Jordan et al., 2013). Land tenure norms are a prime example of niche construction (O'Brien \& Laland, 2012; Shennan, 2011) as their evolution has shaped the nature of inequality and intergenerational transfers, restructuring the selective pressures facing early cultivators (Gibson \& Gurmu, 2011; Kushnick, 2010; Voland \& Dunbar, 1995). Further, the

\footnotetext{
* Corresponding author at: Impal Marriage Project, Kabanjahe, North Sumatra, Indonesia. E-mail address: kushnick@hotmail.com (G. Kushnick).
}

emergence of immovable property may have changed prevailing patterns of postmarital residence and an understanding of land tenure evolution is thus a crucial link in the chain of evidence needed to explain genetic diversity (Jordan, Gray, Greenhill, \& Mace, 2009; Oota, Settheetham-Ishida, Tiwawech, Ishida, \& Stoneking, 2001; Wilkins \& Marlowe, 2006).

Here we adopt a rigorous phylogenetic approach to modelling the evolutionary trajectories of land tenure norms in Austronesian societies (Gray, Greenhill, \& Ross, 2007; Mace \& Pagel, 1994; Nunn, 2011). Our approach is multifaceted, and includes: (a) testing for phylogenetic and geographic signal in land tenure norms, (b) testing for relative support amongst competing linear and nonprogressive models of evolution, and (c) reconstructing ancestral states. Developed in evolutionary biology, phylogenetic approaches have sometimes met skepticism when applied to understanding cultural evolution. Not least amongst these criticisms is that the approach assumes that norms are transmitted vertically, downplaying the possibility of independent invention (i.e., convergent evolution) and diffusion (i.e., horizontal transmission). Despite early detractors (e.g., Borgerhoff Mulder, Nunn, \& Towner, 2006; Boyd, Richerson, Borgerhoff Mulder, \& Durham, 1997), phylogenetic approaches have a growing body of empirical studies that attest to their utility (e.g., Currie, 2013; Gray et al., 2007; Mace \& Jordan, 2011).

Austronesian-speaking communities are a particularly apt set of populations for addressing this issue. First, the Austronesian expansion saw groups spread through the Pacific in pulses and pauses 
(Gray, Drummond, \& Greenhill, 2009), initially intermingling with pre-existing populations in Island Southeast Asia and New Guinea, and then to an array of virgin lands where the prevailing socioecological conditions might have selected for rapid cultural macroevolutionary diversification. Second, the predominantly island environments occupied by this group of societies can be seen as a "laboratory for the study of cultural adaptation" (Sahlins, 1958: x). Third, the group is largely composed of cultivators and, thus, land is central to their lifestyles; the common ancestral communities were likely to be societies of Neolithic farmers, and most of the descendant populations retain some sort of agrarian component (Diamond \& Bellwood, 2003). Fourth and pragmatically, excellent language phylogenies are available, as are data on land tenure (Greenhill, Blust, \& Gray, 2008).

\section{Evolution of land tenure norms}

Late 19th-Century explanations for diversity in land tenure systems were framed in terms of unilineal evolution (de Laveleye, 1874; Engels, 1884; Maine, 1876; Morgan, 1877). For instance, in de Laveleye (1874), societies progressed from a nomadic phase without land ownership, to agrarian pastoral phase within which land was held by groups with usufruct rights given to individuals. From there, they progressed into the agricultural phase within which land rights were held by patrilineal kin groups and from there to a phase within which individual cultivators held ownership. In no uncertain terms, the trajectory of change in his account, illustrated in Fig. 1a, was a rectilinear (i.e., one-way) progression: "It is only after a series of progressive evolutions and at a comparatively recent period that individual ownerships, as applied to land, is constituted" (p. 3). This sequential, progressive view of social evolution has long fallen from favour (Carneiro, 2003; Currie, Greenhill, Gray, Hasegawa, \& Mace, 2010; Currie, Greenhill, \& Mace, 2010; Currie, Greenhill, \& Mace, 2010; Sanderson, 2007), but this is partly because macroevolutionary hypotheses about the structure of evolutionary trajectories have been difficult to test (Currie \& Mace, 2011).

More recent approaches posit less restrictive evolutionary trajectories. For instance, Smith (1988) elaborates a model for hunter-gatherers that starts with a continuum of "ideal types" of land tenure from least- to most-exclusive land-use rights (illustrated in Fig. 1b). Where any given society falls along this line is a function of the benefits and costs of excluding others, which is in turn a function of the density and predictability of resources within the local socioecological context, and the benefit of having accurate information about prey abundance. Another example with perhaps more relevance for Austronesian cultivators is provided by Netting (1993).
In his framework, concerns for land ownership arise with a shift to an agrarian economy. Swidden cultivators live at relatively low densities and use plots of lands discontinuously. They have no reason to make perpetual claims to land and so usufruct rights are common. With increasing population density, descent group territoriality arises. Private landownership norms arise with agricultural intensification. These ecological frameworks by no means require a progressive view of social evolution, but implicit in their use of a continuum is the sequential element that early evolutionists thought primary.

Studies of land tenure evolution are handicapped by the dearth of documented transformations. Amongst Austronesian societies, for instance, the majority of historically documented changes in land tenure occurred under colonial, legal, and conflict-related pressures. These pressures are likely different to the ones driving land tenure evolution before European contact and so do not provide a reasonable general model (Alkire, 1974; Goh, 1998; Utrecht, 1969). Another potential source of data is the archaeological record. Despite a strong understanding of prehistoric settlement patterns in early Austronesian societies of Southeast Asia (Bellwood, 2007) and Oceania (Kirch, 2000), the archaeological record provides evidence for only indirect inferences about land tenure norms and their transitions in a few very specialised cases (Dye, 2010; Earle, 1998, 2000; Kirch \& O'Day, 2003; McCoy et al., 2011).

The problem is much the same for a third potential source of datahistorical linguistics (Goda, Keesing, \& Blust, 1980; Pawley, 2005). The term *kainanga, indicating a land-holding corporate kin group, has been reconstructed for Proto-Oceanic and Proto-Polynesian (Marck, 2010). This suggests that kin-group based tenure was present in early Oceanic societies ca. 3,500 ya, and continued to be an important feature of Polynesian land ownership. Beyond this, terms for 'land', 'garden', 'fence' and 'swidden' are not semantically transparent with respect to ownership (Ross, Pawley, \& Osmond, 1998). Finally, no current linguistic evidence is suggestive of one type of ancestral land tenure form over another for the western Austronesian societies.

\section{Methods}

We used computationally intensive phylogenetic methods (Gray et al., 2007; Mace \& Pagel, 1994; Nunn, 2011) derived from evolutionary biology to reconstruct the evolution of land tenure norms among Austronesian societies. We adopted an approach to making inferences about ancestral states in changes in social organisation that Jordan et al. (2009) have dubbed "virtual archaeology". In particular, we: (a) calculated phylogenetic signal for land tenure norms, and measured this against "geographic signal"; (b) modelled the evolutionary trajectories of land tenure norms using

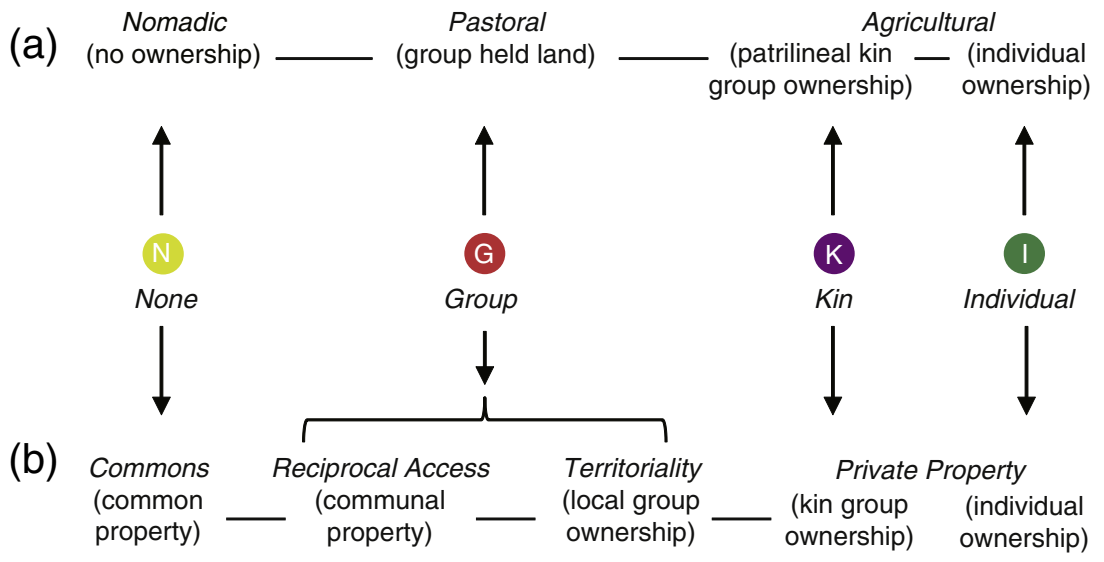

Fig. 1. Land tenure norms from (a) de Laveleye (1874) and (b) Smith (1988) compared to the coding of norms used in this paper. 
maximum likelihood methods; and, (c) used maximum likelihood and node fossilisation to constrain the evolutionary process and test hypotheses about ancestral states.

\subsection{Land tenure data}

We used a sample of 97 societies for our analyses (see Fig. 2a). To be included in our sample, societies had to meet two criteria: (1) they had to be included in the Austronesian Basic Vocabulary Database (ABVD; Greenhill et al., 2008); and (2) there had to be information about land tenure norms in their entry in at least one of the three relevant volumes of the Encyclopedia of World Cultures (Levinson \& O'Leary, 1996a, 1996b, 2002) or the two relevant volumes of Ethnic Groups of Insular Southeast Asia (LeBar, 1972, 1975). We matched ABVD entries to encyclopedia entries using society names and geographic coordinates from one of the co-authors' previous publications (Jordan et al., 2009). The raw data on land tenure used in our analyses are included in Table S1 (see Supplementary Materials, available on the journal's website at www.ehbonline.org), and illustrated in the colour-coded points on the map in Fig. 2a.

Land tenure norms were coded using a four-pronged scheme, illustrated in Fig. 1, that incorporates elements of existing schemes (de Laveleye, 1874; Netting, 1993; Smith, 1988). The categories were determined $a$ priori and were theoretically motivated. Where possible, "traditional" norms were favoured over those arising from recent external pressures. "No ownership" (N) was defined as the absence of permanent land tenure. For instance, among the Agta from Luzon, Philippines, land ownership is a "foreign concept...they see land as a free good" (Headland, 1996, p. 5). "Group ownership" (G) was defined as land tenure held by corporate entities composed of a mix of related and unrelated individuals, such as villages. For example, among the Bonerate of Nusa Tenggara, Indonesia, "agricultural land is collectively owned by the villagers; plots for cultivation are allocated by the village headman" (Broch, 1996, p. 44). "Kin ownership" (K) was defined as land tenure held by corporate entities of related individuals, such as lineages or bilateral kindred. For example, amongst the Choiseul Islanders, "ownership of land is by kin groups known as sinagge" (Scheffler, 1996, p. 38). Finally, "Individual ownership" (I) was defined as private land tenure to individuals. For instance, among the Tongareva of Polynesia, "palms and land were vested in individuals rather than groups" (Roscoe, 1996, p. 340).

Many of the societies ( $n=64$ ) had only one land tenure norm, but about a third of them $(n=33)$ had more than one of these norms present for different classes of land, or for different segments of society. For our analyses, each society was assigned a main land tenure norm defined as the one that applied to the largest segment of a society's population. We attempted to use polymorphic coding in initial analyses, but this approach was precluded by the size of the data set and thus the statistical power of the approach for both maximum-likelihood and Bayesian analyses. The original sample had 101 societies, but we pared it down to 97 because 4 societies would have ended up with misleading values under this coding scheme. For instance, in Hawai'i the land tenure norms include both private ownership by elites and non-ownership (i.e., usufruct rights) for the masses. In our coding scheme, we would have called this a nonownership (N) society, but clearly it is not, as elite ownership of land is an oft-noted aspect of this society (e.g., Earle, 1998).

We did not exclude all societies with elements of elite ownership. In Tahiti, for instance, the "chiefly and commoner classes" are allowed to own land, but the "lower class, known as teuteu" are not (Ferdon, 1996, p. 306). We labelled Tahiti an individual (I) ownership society despite restrictions on the ability to own land based on socioeconomic position. There are a number of papers that address the evolution of elite land tenure (Dye, 2010; Earle, 1998, 2000; Kirch \& O'Day, 2003; McCoy et al., 2011), including a recent one (Currie, 2013) that adopts a phylogenetic perspective similar to ours.

\subsection{Phylogenetic trees}

We used language trees derived from the ABVD-cognate sets of a 210-item word-list from over 600 Austronesian languages (Greenhill et al., 2008). The posterior distribution of trees was inferred from these data using Bayesian Markov-chain Monte Carlo (MCMC) methods (Huelsenbeck, Ronquist, Nielson, \& Bollback, 2001; Yang \& Ranalla, 1997). Bayesian MCMC approaches allow us to quantify the uncertainty in any phylogenetic tree model, making these methods particularly important for cultural evolutionary systems where a single branching tree is unlikely to accurately represent human population history (Boyd et al., 1997; Pagel \& Meade, 2006). The languages, trees, and their properties are described more fully elsewhere (Gray et al., 2009). The analyses were carried out on two sets of trees: those with branch lengths proportional to lexical change, and those where branch lengths are proportional to time. We primarily report the results of analyses on the lexical-change trees because language change is likely to track cultural change induced by contact or drift processes, but where the time-scaled trees produced substantive differences we report those and discuss their implications.

We pruned the trees to retain those languages for which we had corresponding data on land tenure norms $(n=97)$. Properties of the trees, such as branching patterns and branch lengths, were represented in proportion their posterior probability. We computed the maximum clade credibility (MCC) tree in the TreeAnnotator package of BEAST v.1.7.2 (Drummond, Suchard, Xie, \& Rambaut, 2012). The maximum clade credibility tree is the tree from the posterior distribution that has the highest overall score of clades appearing in all trees in the posterior. This tree was used to visually summarise the posterior in Fig. 2b. Note that the branch lengths for Sengseng and NehanHape have been shortened to $60 \%$ of their original length to fit the illustration. The comparative analyses, however, were performed over all 1,000 trees.

\subsection{Phylogenetic and geographic signal}

We tested the degree of phylogenetic signal in the land tenure data using the method for discrete characters proposed by Fritz and Purvis (2010). This method takes the sum of sister-clade differences as the basis for determining if variability in traits at the tips of the tree is as a result of "clumping" through shared ancestry on the one hand or random distribution on the phylogeny on the other. We used the "phylo.d" function in the R package "caper" (Orme, Freckleton, Petzoldt, Fritz, \& Isaac, 2011) to estimate the D statistic and its associated $p$-values for each of the four land tenure norms across the 1,000 trees in the posterior, with 10000 permutations for each. When $D=0$, it indicates phylogenetic clumping following Brownian motion, while $D=1$ indicates the trait is random with respect to the phylogeny. Values can also be less than zero, indicating nonBrownian (i.e. conserved or adaptive) phylogenetic signal, and more than one, indicating overdispersion.

In order to examine whether diffusion according to geographic proximity was an explanatory factor in Austronesian land tenure, we also used this technique to gauge the degree of "geographic signal" in the land tenure data by estimating the $D$ statistic over a geographic "tree." The tree was constructed using geographical distances calculated for each pair of societies, as described in Greenhill and Gray (2012). We use this approach because, while often phylogenetic and geographic distance will be highly correlated, in this particular Austronesian case those correlations are small (Greenhill \& Gray, 2012).

\subsection{Maximum likelihood analyses}

\subsubsection{Evolutionary trajectories}

To reconstruct the evolutionary trajectories of land tenure norms, we used the phylogenetic comparative method Multistate implemented in BayesTraits (Pagel, 1999; Pagel \& Meade, 2006; Pagel, Meade, \& Barker, 

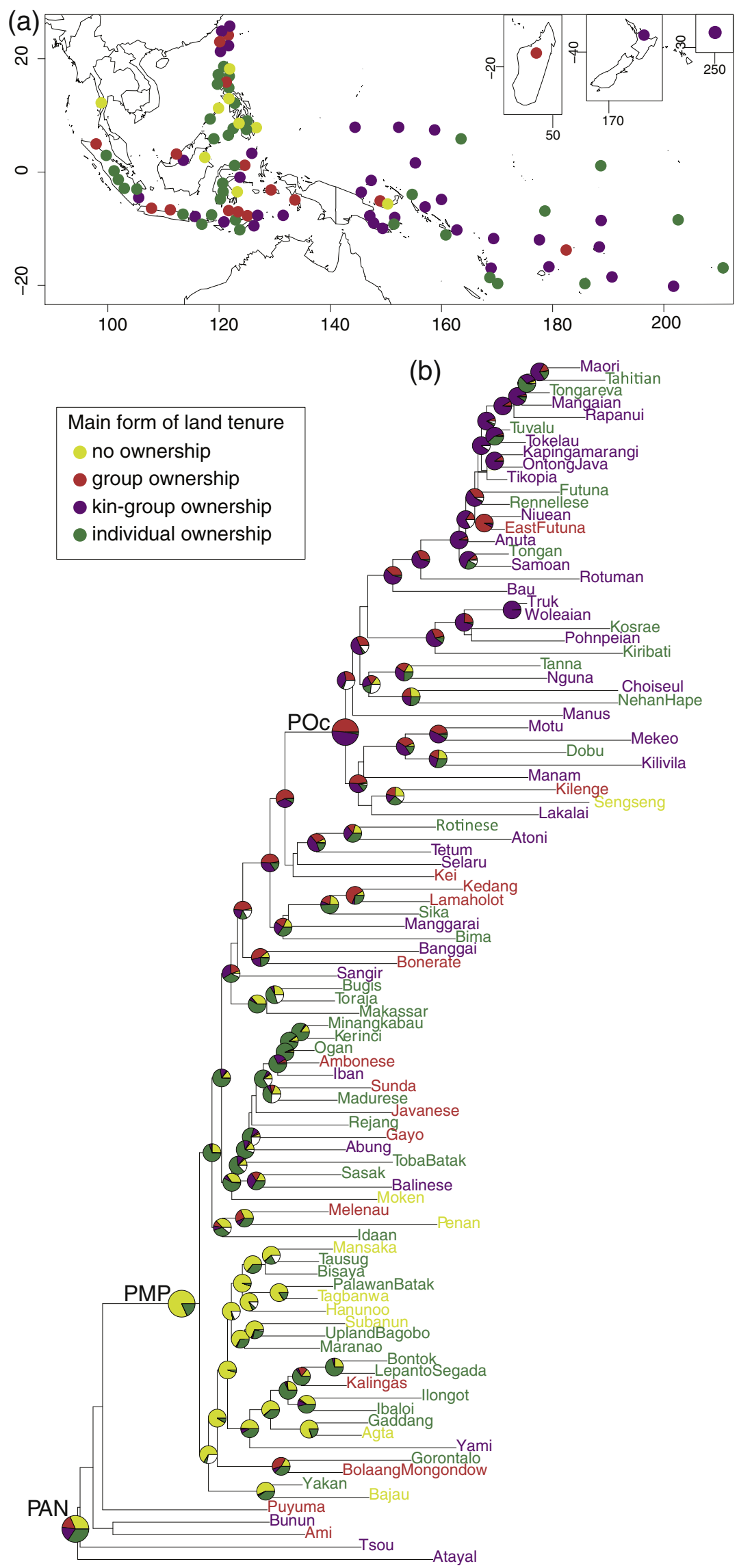

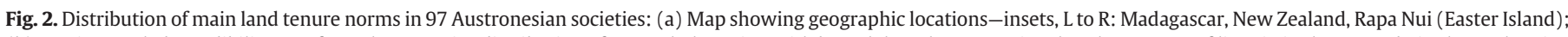

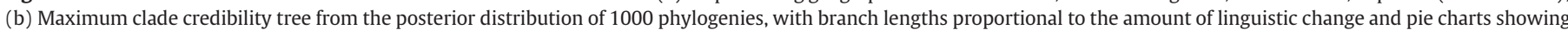
probabilistic reconstruction of ancestral states. 
(a)
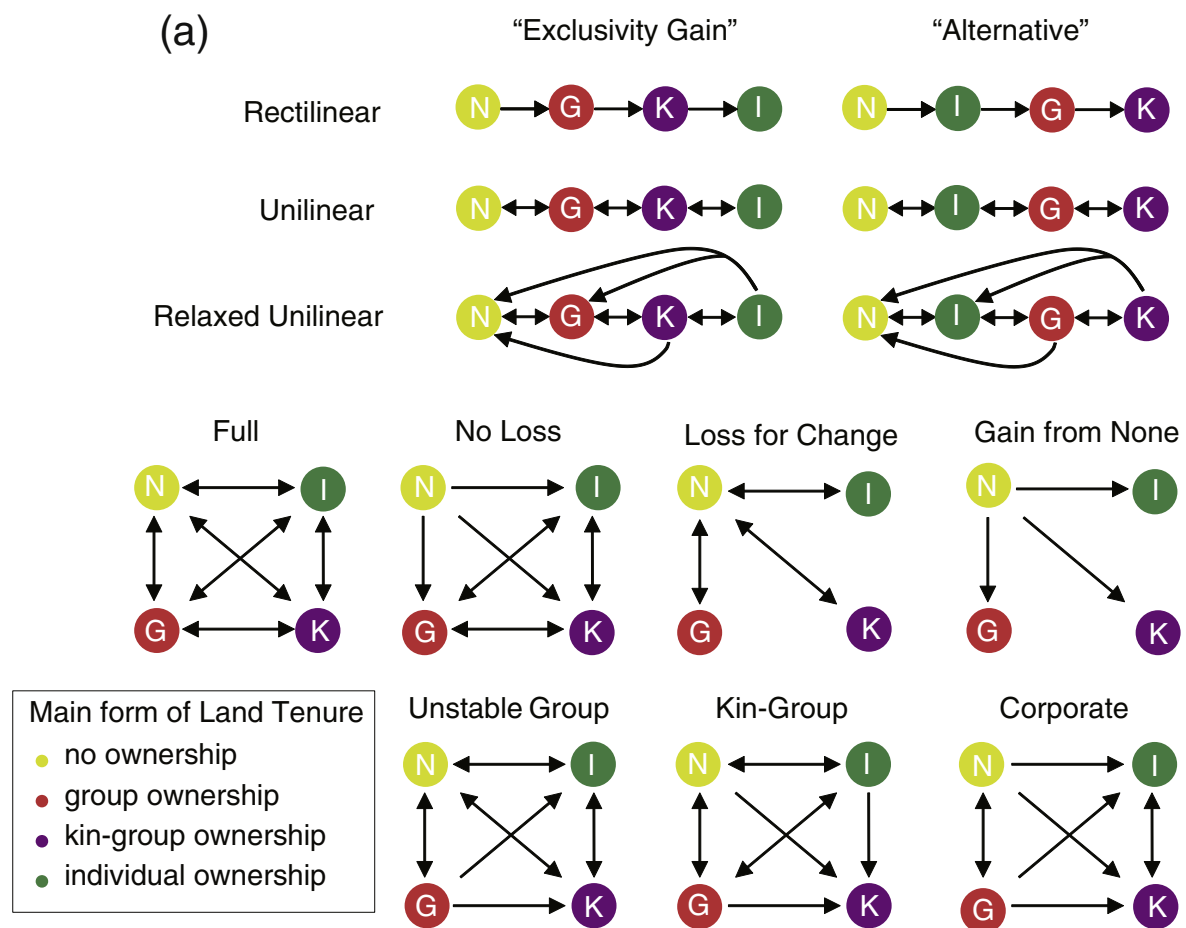

Kin-Group
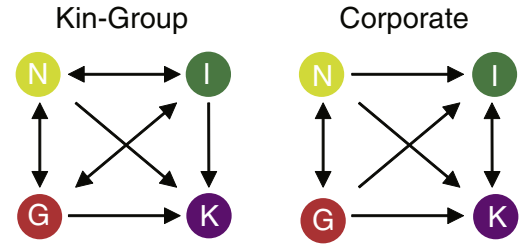

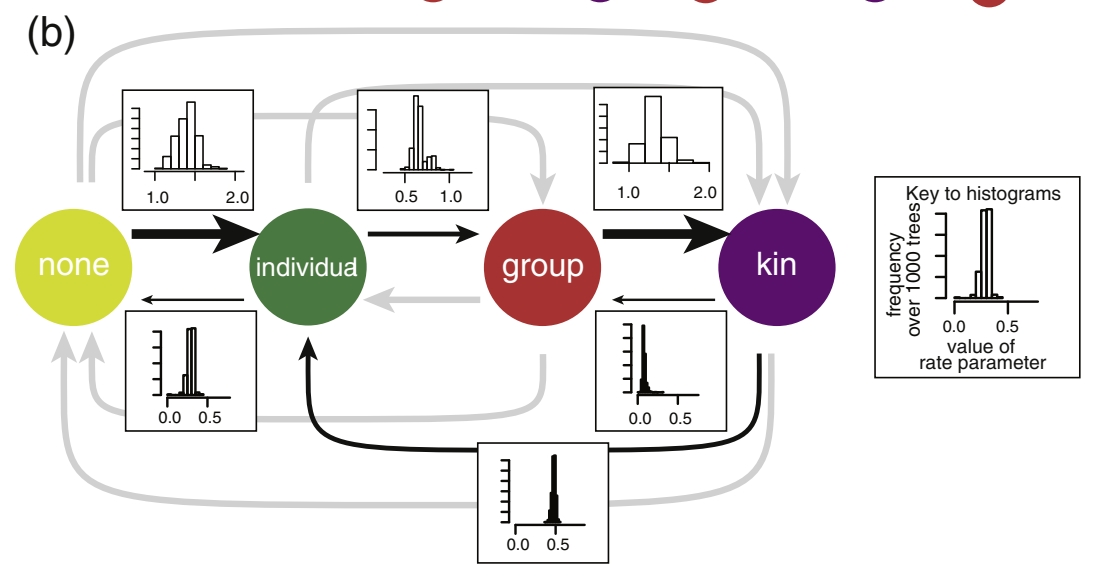

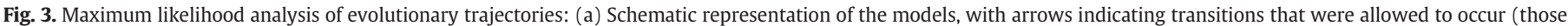

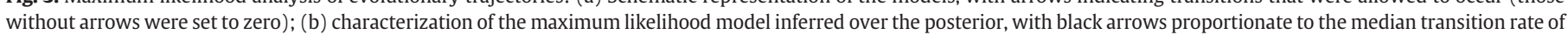
change accompanied by a histogram showing rate variation, and pale grey arrows indicating transitions that were zero in $>95 \%$ of trees.

2004). This method allows us to estimate the underlying model of evolutionary change between different trait classes. Given the comparative data and tree sample, it uses a continuous-time Markov model to describe the evolution of the trait of interest along the branches of a phylogeny. In these analyses, the main land-tenure norm can switch repeatedly between its four states in any of the branches of a tree. Rate parameters specify the rate of change from one state to another: the transition between 0 and 1 is denoted $q_{01}$, and that between 1 and 3 as $q_{13}$, and so forth. These rates define the probabilities of each of these changes, and therefore both the character states at internal nodes on a tree and the overall likelihood of the data (Pagel, 1994, 1999). As well as obtaining the rate parameters of the maximum likelihood solution for each of the 1,000 phylogenies (for both the lexical and time-scaled trees), we characterised a number of different models of land tenure evolution by restricting some parameters to take zero values.

Maximum likelihood analyses (Huelsenbeck \& Crandall, 1997; Johnson \& Omland, 2004; Pagel, 1999) were performed to character- ise the range of the model parameters at the maximum likelihood solutions for the main type of land tenure. We ran these analyses both with and without the covarion that allows for different rates of change in traits across the tree. For each transition the upper range of rate parameters was higher under the covarion, but the relative patterns of change did not vary substantially and the range of the likelihoods overlapped considerably, so we used the non-covarion analyses for further tests. For each model and for each of the 1,000 trees (for both the lexical and time-scaled trees), we used the likelihood scores to calculate the model's AIC as $2 \mathrm{k}-2 \ln L \mathrm{~h}$ where $\mathrm{k}$ is the number of parameters that are free to vary. The full and unrestricted model has 12 free parameters.

For completeness we also searched the combined parameter space of trees and models using the reversible-jump MCMC implementation of Multistate in BayesTraits. Although the Random Jump MCMC procedure theoretically works to reduce the transition rate parameters to tractable dimensions, we found that our chains had a difficult time converging because of what seemed to be a 
Table 1

Phylogenetic signal of each of the main type of land tenure norms ( $n=97$ ).

\begin{tabular}{llll}
\hline \multirow{2}{*}{$\begin{array}{l}\text { Land } \\
\text { Tenure }\end{array}$} & D-Statistic & & Phylogenetic Signal? \\
\cline { 2 - 3 } & Median $^{2}$ & Range & \\
\hline None & 0.30 & $-0.09-0.64$ & Moderate \\
Individual & $1.19^{* * *}$ & $0.98-1.34$ & Significant absence \\
Group & $0.87^{*}$ & $0.62-1.09$ & Significant absence \\
Kin-Group & $0.17^{* * *}$ & $-0.04-0.29$ & Significant and strong \\
\hline
\end{tabular}

$1 \mathrm{D}$ and $p$-values estimated from all 1,000 trees in the posterior.

$2 * 95 \% p<0.05 ;{ }^{* * *}$ all $p<0.005$.

relatively flat likelihood surface and the amount of variation in the data. Ten chains were run for more than two billion iterations each, and their Lh values ended up within the same range, but the chains found it difficult to come to convergence. We thus preferred the simpler approach of testing pre-specified models with the maximum likelihood approach (Huelsenbeck \& Crandall, 1997; Johnson \& Omland, 2004; Pagel, 1999).

\subsubsection{Competing models}

We tested among a handful of models of evolutionary trajectory, illustrated in Fig. 3a. The first set of evolutionary trajectory models that we tested amongst incorporates the sequential elements of early evolutionism as described by Carneiro (2003), and is similar to those used by Currie, Greenhill, Gray, Hasegawa, and Mace (2010); Currie, Greenhill, and Mace (2010); Currie, Greenhill, and Mace (2010). These models feature both the N-G-K-I trajectory ("exclusivity gain") featured by early evolutionists and suggested by the continua of more recent ecological anthropologists, and the N-I-G-K trajectory ("alternative") that was suggested by parameter estimates of the full model that included all potential transitions. The rectilinear models allow a stepwise progression without reversal. The unilinear models allow stepwise progression and regression. The relaxed unilinear models allow for stepwise progression, but regression is unconstrained rather than stepwise.

The second set of models (also illustrated in Fig. 3a) includes a number of non-progressive variants, including the full model with all four types of land tenure and transitions to and from each. The no-loss model allows all transitions, except back to N. The loss for change model allows change to and from any type of land tenure with the stipulation that all changes must pass through $\mathrm{N}$, mimicking the possible culturalevolutionary scenario of a voyaging population. Similarly, the gain from none model allows all forms of land tenure to emerge from $\mathrm{N}$, but regression is impermissible. The unstable group model allows all transitions except that $\mathrm{G}$ can only emerge from $\mathrm{N}$. The kin-group model allows all transitions except the loss of $\mathrm{K}$. The corporate model allows all transitions except that once $\mathrm{K}$ or I arise, there can only be changes between them.

\subsubsection{Ancestral state estimation and node fossilisation tests}

We inferred the probability of each form of land tenure at each node of the MCC tree with the ML implementation of Multistate in BayesTraits (shown in Fig. 2B). We also targeted three important nodes: Proto-Austronesian (PAN), Proto Malayo-Polynesian (PMP), and Proto Oceanic (POc), in order to test the ancestral state inferences. We "fossilised" each of these separately to take each of the four states of land tenure in turn and re-ran the maximum likelihood model across all 1,000 trees (Pagel et al., 2004). This technique allowed us to constrain the evolutionary process to reflect each hypothesis about ancestral states. We then compared the likelihood of each fossilised state to each other state on each tree, using the likelihood ratio test.

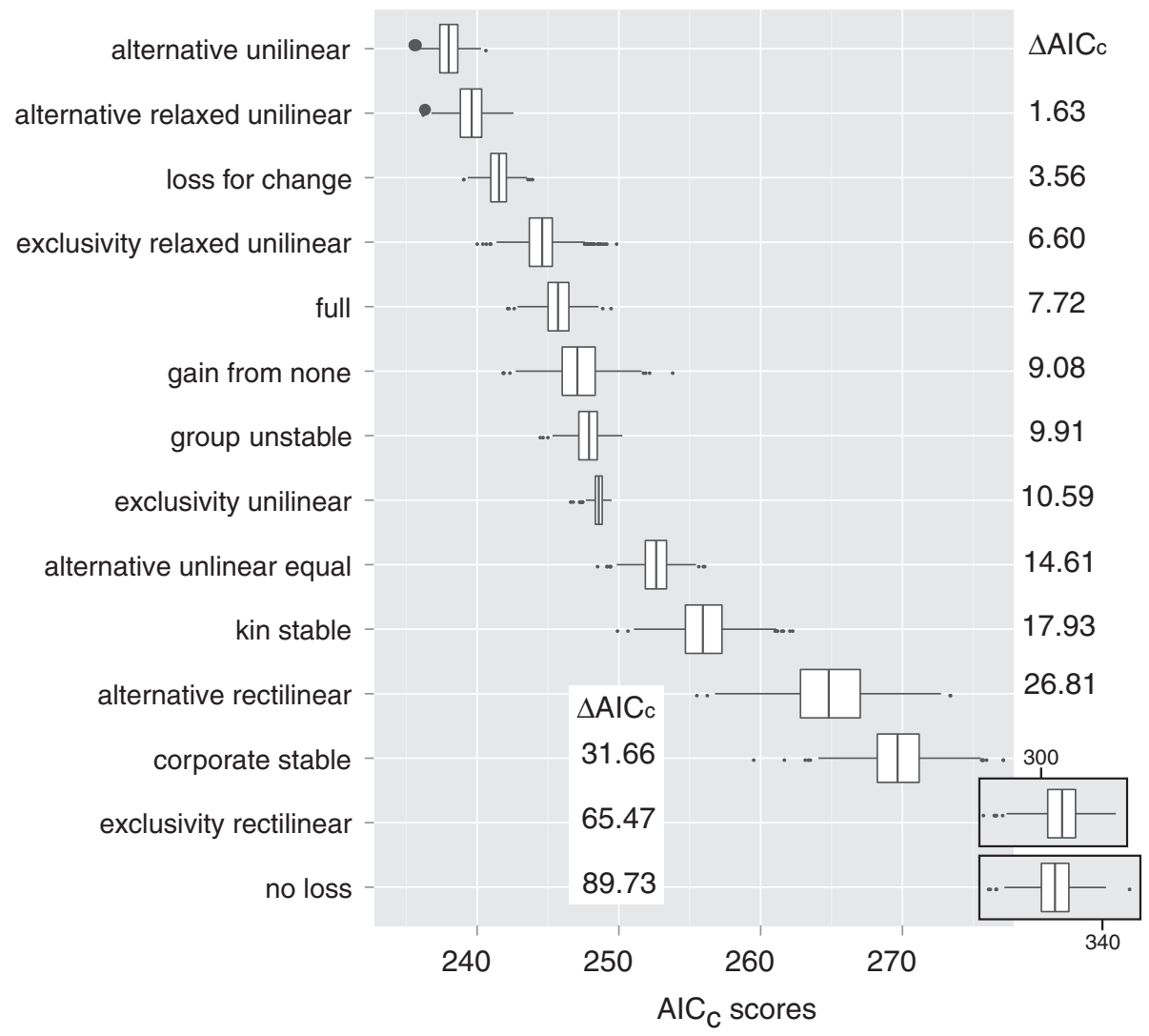

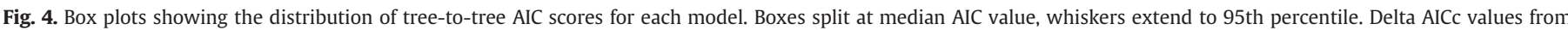
median values are given adjacent to each box plot. 


\section{Results}

\subsection{Phylogenetic and geographic signal}

Estimates of the $D$-statistic (Fritz \& Purvis, 2010) over the posterior sample of 1000 lexical phylogenies for each land tenure norm are presented in Table 1 . The values for group $(G)$ were close to one (median $=0.87$ ) and significantly different from zero, meaning that there is a lack of "clumping" of these norms on the tree i.e. they do not have strong phylogenetic signal. Values for I are also significantly different from zero and mostly greater than one (median $=1.19$ ), indicating overdispersion, i.e. that closely related societies are actually more different than expected. The same pattern was found for the geographic estimates for $\mathrm{G}(D=0.77, p=0.0002)$ and $\mathrm{I}(D=1.13$, $p=0$ ), which were both significantly different from zero and thus not explained by geographic structure. Thus, spatial or linguistic proximity does not predict which societies have group- or individually-based land tenure norms. The $D$-value for none $(\mathrm{N})$ on the language trees was midway between 0 and 0.64 , and not statistically different from zero, suggesting that any observed clumping could not be ruled out as chance. However, when estimated on the geographic tree, the $D$-statistic for $\mathrm{N}$ was 0.88 , significantly different from 0 ( $p=0.002$ ), indicating that geographic distance had no structuring effect on the land tenure norm "none." Finally, the values for $\mathrm{K}$ were close to zero (median $D=0.17$ ) and significantly different from one on the lexical phylogenies, meaning that societies with kin-based land tenure tended to be clustered together on the phylogenies and may share this norm due to inheritance from ancestral communities. When estimated on the geographic tree, the $D$-statistic for K was 0.55 , but significantly different from 0 ( $p=$ 0.002 ), indicating that geographic distance had less structuring effect on this land tenure norm.

\subsection{Evolutionary trajectories}

We assessed the likelihood of models (Fig. 3a) ranging from sequential trajectories like those favoured by early evolutionists, to less restrictive ones lacking sequential elements. We started by estimating the likelihood of a series of models, including nonsequential models, and a series of sequential models built on the $\mathrm{N}-\mathrm{G}-\mathrm{K}-\mathrm{I}$ sequence suggested by the existing literature (i.e., the "exclusivity gain" models). When we compared these with the full model with all possible transitions (shown in Fig. 3b), the N-I-G-K trajectory had higher likelihood values. This suggested that the evolution of these norms followed an alternative trajectory to those previously proposed. We then built and estimated the likelihood of a series of sequential models around the N-I-G-K trajectory (i.e., the "alternative" models). Fig. 4 shows that the resultant AIC values most strongly supported the unilinear ("alternative") model. Two other models received some support, relaxed unilinear ("alternative") and loss for change. The remaining models were comparatively unsupported.

We then assessed each of these models over trees with branch lengths scaled to time. AIC scores for each model by tree are presented in Table S2 (see Supplementary Materials, available on the journal's website at www.ehbonline.org). As with the initial analyses, the timescaled trees most strongly supported the unilinear ("alternative") model. The relaxed unilinear ("alternative") and the loss for change models received some support. The remaining models were comparatively unsupported. The most substantive differences are that the "no loss" and the rectilinear ("alternative") model both now receive more support than the full model. A notable pattern emerges for the "alternative" model forms: three have support better than the full model and close to the best model, while this applies to only one of the "exclusivity" models. Finally, the dynamics of the full model (Fig. 3b) inferred on the time-scaled trees reflect those inferred on the lexical-change trees (i.e., N-I-G-K). The only difference is that $\mathrm{G}$ to $\mathrm{N}$ and $\mathrm{G}$ to I transitions have very low relative rates, but are no longer effectively zero.

\subsection{Ancestral state reconstruction}

The pie charts on the phylogeny in Fig. 2b show the inferred probability of each form of land tenure at each node under the "full" model, that is, when parameters were allowed to take their maximum likelihood values. Ancestral states for Proto-Austronesian (PAN), Proto-Malayo-Polynesian (PMP), and Proto-Oceanic (POc) were tested using a node "fossilization" procedure. The results, illustrated in Fig. 5, are as follows: There was no evidence for any of the land tenure types to be favoured at PAN, as all likelihood-ratio tests were non-significant. At PMP, nodes fossilised to I or $\mathrm{N}$ are favoured over $\mathrm{K}$ and G. At POc fossilizations rule out N, and favour K or G. The pattern of inferences at these nodes is the same for both lexical- and timescaled trees (analyses not shown). It is particularly unsurprising that PAN is difficult to infer given the diversity of the early-branching Formosan societies.

\section{Discussion}

We used rigorous phylogenetic methods to model the evolution of land tenure norms in 97 Austronesian societies. By reconstructing the pattern of historical change in these societies, our analyses represent an important step toward understanding the bedrock of human society-one that transformed the selective landscape for Neolithic humans (Shennan, 2011) and paved the way for the evolution of cooperation, inequality, and large-scale society (Jordan et al., 2013). According to Sanderson (2007) "establishment of the sequence in and of itself explains nothing, of course, but it certainly provides a solid basis on which the construction of explanations of process can be built." The most strongly supported model, and one of the two that were partially supported, was characterised by the N-I-G-K trajectory. This is surprising for two reasons.

First, cultural evolution along a sequential evolutionary trajectory has long been disfavored by social scientists (Carneiro, 2003; Currie \& Mace, 2011; Sanderson, 2007). Currie and Mace (2011) highlight the following criticisms of the approach: (a) it is typological-societies are viewed as progressing through well-defined stages but, in reality, the boundaries are less distinct; (b) it focuses on progression but many societies have gone through processes of regression; and (c) it is ethnocentric. Carneiro (2003) points out that much of the criticism is based on misunderstanding. For instance, early evolutionists did not necessarily argue that social evolution progressed along a rectilinear (i.e., one-way) trajectory, nor that all societies necessarily passed through all phases. Regardless, there is increasing empirical support for unilineal models (Bondarenko, Grinin, \& Korotayev, 2002; Carneiro, 1968, 1970, 2003), including "Spencerian" traits (i.e., those that change via increases in complexity) such as sociopolitical organisation in Austronesian and Bantu societies (Currie, Greenhill, Gray, Hasegawa, \& Mace, 2010; Currie, Greenhill, \& Mace, 2010; Walker \& Hamilton, 2011). The suite of sophisticated computational methods used in ours and related studies allows for the detection of these trajectories by searching immensely large parameter spaces that cannot be explored by intuition or by hand.

Second, the N-I-G-K trajectory supported by our analyses contradicts the one favoured by early evolutionists and ecological anthropologists (see Fig. 1), as well as some ethnographic accounts of changes in land tenure norms. Late nineteenth-century evolutionists believed that land tenure norms progressed along the following universal trajectory: N-G-K-I (de Laveleye, 1874; Engels, 1884; Maine, 1876; Morgan, 1877). Ecological and economic anthropologists have favoured a continuum of land tenure types that implies the same sequence (Netting, 1993; Smith, 1988). In some ethnographic accounts, elements of this sequential 
(a)
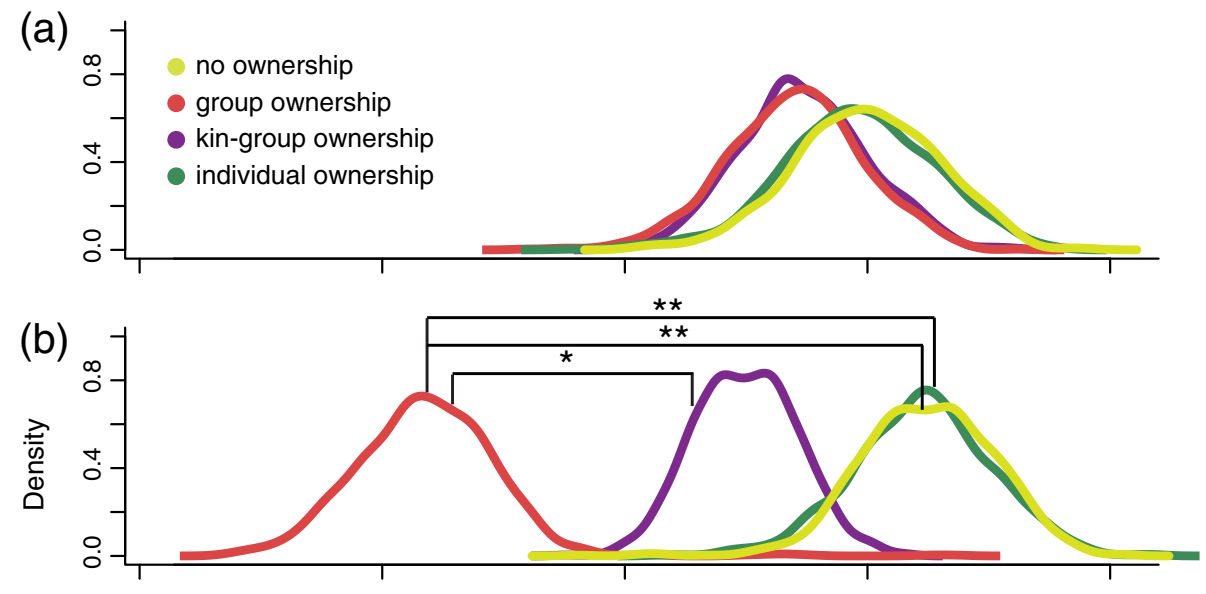

(c)

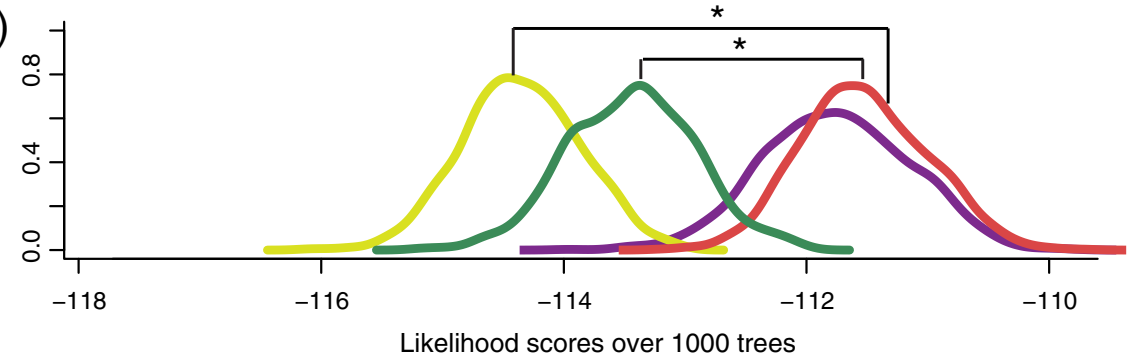

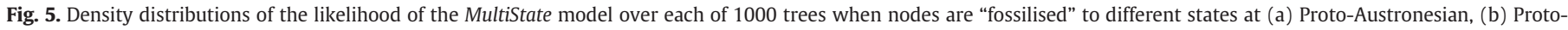

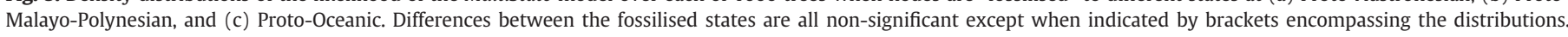
${ }^{*} p<0.5$ for at least $95 \%$ of the tree sample, ${ }^{* *} p<0.01$.

trajectory are implied, such as in Damas's (1994) detailed study of land tenure on the Micronesian atoll Pingelap.

Despite the relative dearth of documented changes in land tenure norms in the ethnographic and archaeological records (Earle, 2000), one well documented example follows the sequential trajectory supported by our analyses. The Javanese practice a form of $\mathrm{G}$ that most likely arose out of individual ownership in the historical past (Goh, 1998). Javanese land tenure was a central piece of de Laveleye's (1874) reconstruction of the universal progression favored by early evolutionists but not supported by our analyses (interestingly, an anonymous letter published in 1880 [Anonymous, 1880], criticised de Laveleye [1874] reconstruction in favour of one that resembles ours). The transition from $\mathrm{G}$ to I among the Javanese likely arose in response to the Dutch colonial "Cultivation System" of 1830 whereby peasant farmers were compelled to provide a percentage of their harvests for exports (Goh, 1998). The shift to G allowed them to "game" the system for their own economic benefit. The problem with this example is that the changes were driven by legal and colonial pressures, which are too unlike those driving change in land tenure over the span of Austronesian prehistory to serve as a reasonable generalisation.

Since first being adopted from evolutionary biology to study cultural evolution (Mace \& Pagel, 1994), cultural phylogenetics have amassed an impressive empirical portfolio (see, e.g., Gray et al., 2007, or Mace \& Jordan, 2011), ranging from studies of the evolution of social structure (Jordan et al., 2009) to folktales (Tehrani, 2013). This is not to say that cultural phylogenetic approaches have been without controversy. To the contrary, the usefulness of the approach has been questioned by a number of scholars (e.g., Borgerhoff Mulder et al., 2006; Boyd et al., 1997). Much of this criticism centers on whether vertical transmission sufficiently characterises cultural evolution to warrant the application of phylogenetic models (see discussions in: Borgerhoff Mulder et al., 2006; Gray et al., 2007). Although caution is certainly warranted, a number of studies support the position that the criticism is too harsh (e.g., Collard, Shennan, \& Tehrani, 2006; Currie,
Greenhill, Gray, Hasegawa, \& Mace, 2010; Currie, Greenhill, \& Mace, 2010). To address diffusion, we re-ran our phylogenetic signal analyses over a "tree" derived from geographic distances. The results were congruent with the phylogenetic signal analyses insofar as would be expected from the roughly geographic spread (west to east) of Austronesian languages, but importantly indicate that for none of the four types of land tenure does the geographic distance account for more signal than the phylogenetic structure.

As our analysis of phylogenetic signal revealed, there is significant clustering of K, especially in Oceanic societies. Goodenough (1955) viewed this, and the presence of similar norms in geographically diverse Austronesian societies, as evidence that PMP was probably characterised by $\mathrm{K}$, resembling the oo and kainga that he had documented ethnographically in the Gilbert Islands (Goodenough, 1951). Our reconstruction of ancestral states provides no support for this hypothesis, as PMP was probably characterised by $\mathrm{N}$ or I. In light of our analyses, it is more likely that $\mathrm{K}$ in Oceanic societies is of more recent origin. We suggest that POc was characterised by $\mathrm{K}$ or $\mathrm{G}$. One potential explanation is that $\mathrm{K}$ arose as the product of multiple convergent evolutions (Frake, 1956). These results contrast with Currie's (2013) analyses supporting K as the ancestral state for PAN, PMP, and POc. He used a different sample of societies and different coding of land tenure norms. The relative contribution of these two factors for explaining the divergent conclusions remains unclear.

Future work could test adaptive hypotheses about the distribution of land tenure norms in Austronesian societies. Have land tenure norms evolved in response to socioecological conditions, population pressure, physical geographic characteristics of the islands themselves, environmental and subsistence risk and uncertainty, or some combination of factors? Furthermore, are land tenure norms correlated with patterns of residence and descent across Austronesian societies, as anthropologists and linguists (Blust, 1980) have suggested?

One possible scenario meshes well with the evolutionary trajectory supported by our study, as well as with recent work by Kennett, 
Anderson, and Winterhalder (2005); Kennett and Winterhalder (2008) on the ideal free distribution and the spread of Oceanic cultures (Gray et al., 2009). As people expanded onto new islands, there was little initial pressure on land, supporting a status quo in land tenure norms (i.e. phylogenetic inheritance) or to the abandonment of ownership claims. Land would have been sufficient and shifting cultivation would have prevailed. As population pressure increased, land as a public good became untenable (Hardin, 1968), leading to the emergence of I. With further pressure and islands of finite size, people either dispersed to new islands or adopted land tenure norms suitable to the ecology. G could have eased the pressure because people would have shared access to the scarce resource. As people extracted less and less from the shared resource $\mathrm{K}$ would emerge and, in effect, delay dispersals to new islands. Kin selection theory predicts that individuals will have a greater tolerance for clumping when those nearby are relatives (Morris, Lundberg, \& Ripa, 2001). In essence, this model is the macroevolutionary complement to recent microevolutionary work that teases out the demographic and ecological factors that influence individuals' decisions in public goods games (Lamba \& Mace, 2011).

Is the sequential trajectory or Austronesian land tenure evolution generalizable to other sociolinguistic groups? We argue that comparative phylogenetic studies are uniquely suited for answering this question due to the limitations of the archaeological and linguistic data, and no comparable study has been conducted with other sociolinguistic groups. Our intuition is that the transition from $\mathrm{N}$ to I may well be a widespread pattern. Transitions from $\mathrm{G}$ to $\mathrm{K}$ may be idiosyncratic features of Austronesian societies, or at least societies where the cost of range expansion was substantial. On the other hand, Hamilton's (1975) "kin-group" selection perspective suggests, perhaps, that the transition from $\mathrm{G}$ to $\mathrm{K}$ might be a general feature of populations exceeding a threshold social group size. Our comparative approach here paves the way for further empirical tests of commonalities underlying the evolution of land tenure norms. Additional future work should investigate the possibility of systematic correspondences between types of land tenure, differential access to land through postmarital residence, and patterns of sex-specific genetic markers in the Pacific region.

\section{Supplementary Materials}

Supplementary data to this article can be found online at http:// dx.doi.org/10.1016/j.evolhumbehav.2014.03.001

\section{Acknowledgments}

Thanks to Tim Earle, Mark McCoy, the attendees of the Biological Anthropology Seminar Series at the University of Washington, and two anonymous reviewers for useful feedback.

\section{References}

Alkire, W. H. (1974). Land tenure in the Woleai. In H. Lundsgaard (Ed.), Land tenure in Oceania (pp. 39-69). Honolulu: University of Hawai'i Press.

Anonymous (1880). Het individueel en communal grondbezit. Tijdschrift Voor Nederlandsch-Indie, 1, 256-280.

Bellwood, P. (2007). Prehistory of the Indo-Malaysian archipelago (3rd ed.). Canberra: ANU E Press.

Blust, R. (1980). Early Austronesian social organization: the evidence of language Current Anthropology, 21, 205-247.

Bondarenko, D. M., Grinin, L. E., \& Korotayev, A. (2002). Alternative pathways of social evolution. Social Evolution and History, 1, 54-79.

Borgerhoff Mulder, M., Nunn, C., \& Towner, M. C. (2006). Cultural macroevolution and the transmission of traits. Evolutionary Anthropology, 15, 52-64.

Boyd, R., Richerson, P., Borgerhoff Mulder, M., \& Durham, W. H. (1997). Are cultural phylogenies possible? In P. Weingart, P. Richerson, S. D. Mitchell, \& S. Maasen (Eds.), Human by nature: between biology and the social sciences (pp. 355-386). Mahwah, NJ: Lawrence Erlbaum Associates.

Broch, H. (1996). Bonerate. In D. Levinson, \& T. O'Leary (Eds.), Encyclopedia of World Cultures. East and Southeast Asia, Vol. 5. (pp. 43-46). New York: Macmillan Reference USA.
Carneiro, R. L. (1968). Ascertaining, testing, and interpreting sequences of cultural development. Southwestern Journal of Anthropology, 24, 354-374.

Carneiro, R. L. (1970). Scale analysis, evolutionary sequences, and the rating of cultures. In R. Naroll, \& R. Cohen (Eds.), Handbook of methods in cultural anthropology (pp. 833-871). Garden City, NY: The Natural History Press.

Carneiro, R. L. (2003). Evolutionism in cultural anthropology: a critical history. Boulder, CO: Westview Press.

Collard, M., Shennan, S. J., \& Tehrani, J. J. (2006). Branching, blending, and the evolution of cultural similarities and differences among human populations. Evolution and Human Behavior, 27(3), 169-184

Currie, T. E. (2013). Cultural evolution branches out: the phylogenetic approach in cross-cultural research. Cross-Cultural Research, 47, 102-130.

Currie, T. E., Greenhill, S. J., Gray, R. D., Hasegawa, T., \& Mace, R. (2010). Rise and fall of political complexity in island South-East Asia and the Pacific. Nature, 467, 801-804.

Currie, T. E., Greenhill, S. J., \& Mace, R. (2010). Is horizontal transmission really a problem for phylogenetic comparative methods? A simulation study using continuous cultural traits. Philosophical Transactions of the Royal Society B, 365(1559), 3903-3912.

Currie, T. E., \& Mace, R. (2011). Mode and tempo in the evolution of socio-political organization: reconciling 'Darwinian' and 'Spencerian' evolutionary approaches in anthropology. Philosophical Transactions of the Royal Society B, 366, 1108-1117.

Damas, D. (1994). Bountiful island: a study of land tenure on a Micronesian atoll. Waterloo: Wilfrid Laurier University Press.

de Laveleye, E. (1874). De la proprieté et de se formes primitives (G. Marriott, Trans.). London: MacMillan and Co.

Diamond, J., \& Bellwood, P. (2003). Farmers and their languages: the first expansions. Science, 300, 597-603.

Drummond, A. J., Suchard, M. A., Xie, D., \& Rambaut, A. (2012). Bayesian phylogenetics with BEAUti and the BEAST 1.7. Molecular Biology and Evolution, 29, 1969-1973.

Dye, T. S. (2010). Social transformation in old Hawai'i: a bottom-up approach. American Antiquity, 75, 727-741

Earle, T. (1998). Property rights and the evolution of Hawaiian chiefdoms. In R. C. Hunt, \& A. Gilman (Eds.), Property in Economic Context (pp. 89-118). Lanham, MD: University Press of America.

Earle, T. (2000). Archaeology, property, and prehistory. Annual Review of Anthropology, $20,39-60$.

Engels, F. (1884). Der ursprung derfamilie, des privateigenthums und des staats. (Hottingen-Zurich), Verlag der Schweizerischen Volksbuchhandlung.

Ferdon, E. (1996). Tahiti. In D. Levinson, \& T. O'Leary (Eds.), Encyclopedia of World Cultures. Oceania, Vol. 2. (pp. 305-307). New York: Macmillan Reference USA.

Frake, C. O. (1956). Malayo-Polynesian land tenure. American Anthropologist, 58, $170-173$.

Fritz, S. A., \& Purvis, A. (2010). Selectivity in mammalian extinction risk and threat types: a new measure of phylogenetic signal strength in binary traits. Conservation Biology, 24, 1042-1051.

Gibson, M. A., \& Gurmu, E. (2011). Land inheritance establishes sibling competition for marriage and reproduction. Proceedings of the National Academy of Sciences, 108, 2200-2204.

Goda, T., Keesing, R., \& Blust, R. A. (1980). On early language and early Austronesian social organization. Current Anthropology, 21, 415-419.

Goh, T. (1998). Communal land tenure in nineteenth-century Java: the formation of Western images of the Eastern village community. Canberra: Australian National University.

Goodenough, W. H. (1951). Property, kin, and community on Truk. New Haven, CT: Yale University Press.

Goodenough, W. H. (1955). The problem of Malayo-Polynesian social organization. American Anthropologist, 57, 71-83.

Gray, R. D., Drummond, A. J., \& Greenhill, S. (2009). Language phylogenies reveal expansion pulses and pauses in pacific settlement. Science, 323, 479-483.

Gray, R. D., Greenhill, S. J., \& Ross, R. M. (2007). The pleasures and perils of Darwinizing culture (with phylogenies). Biological Theory, 2, 360-375.

Greenhill, S. J., Blust, R. A., \& Gray, R. D. (2008). The Austronesian basic vocabulary database: from bioinformatics to lexomics. Evolutionary Bioinformatics, 4, 271-283.

Greenhill, S. J., \& Gray, R. D. (2012). Basic vocabulary and Bayesian phylolinguistics: Issues of understanding and representation. Diachronica, 29(4), 523-537.

Hamilton, W. D. (1975). Innate social aptitudes of man: An approach from evolutionary genetics. In R. Fox (Ed.), Biosocial Anthropology (pp. 133-153). London: Malaby Press.

Hardin, G. (1968). The tragedy of the commons. Science, 162, 1243-1248.

Headland, T. (1996). Agta. In D. Levinson, \& T. O'Leary (Eds.), Encyclopedia of World Cultures. East and Southeast Asia, Vol. 5. (pp. 4-6). New York: Macmillan Reference USA

Huelsenbeck, J. P., \& Crandall, K. A. (1997). Phylogeny estimation and hypothesis testing using maximum likelihood. Annual Review of Ecology and Systematics, 28, 437-466.

Huelsenbeck, J. P., Ronquist, F., Nielson, R., \& Bollback, J. P. (2001). Bayesian inference of phylogeny and its impact on evolutionary biology. Science, 294, 2310-2314.

Johnson, J., \& Omland, K. S. (2004). Model selection in ecology and evolution. Trends In Ecology \& Evolution, 19, 101-108.

Jordan, F. M., Gray, R., Greenhill, S. J., \& Mace, R. (2009). Matrilocal residence is ancestral in Austronesian societies. Proceedings of the Royal Society London B, 276, 1957-1964.

Jordan, F. M., van Schaik, C., Francois, P., Gintis, H., Haun, D. B. M., Hruschka, D. J., et al. (2013). The cultural evolution of the structure of human groups. In P. Richerson, \& M H. Christiansen (Eds.), Cultural evolution: Society, technology, and religion (pp. 87-116). Cambridge, MA: MIT Press.

Kennett, D., Anderson, A., \& Winterhalder, B. (2005). The ideal free distribution, food production, and the colonization of Oceania. In D. Kennett, \& B. Winterhalder (Eds.), 
Behavioral ecology and the transition to agriculture (pp. 265-288). Berkeley: University of California.

Kennett, D., \& Winterhalder, B. (2008). Demographic expansion, despotism, and the colonization of east and south Polynesia. In G. Clark, F. Leach, \& S. O'Connor (Eds.), Islands of inquiry: colonisation, seafaring and the archaeology of maritime landscapes (pp. 87-96). Canberra: Australian National University Press.

Kirch, P. (2000). On the road of winds: an archaeological history of the Pacific islands before European contact. Berkeley: University of California Press.

Kirch, P., \& O'Day, S. J. (2003). New archaeological insights into food and status: a case study from pre-contact Hawaii. World Archaeology, 34, 484-497.

Kushnick, G. (2010). Resource competition and reproduction in Karo Batak villages. Human Nature, 21, 62-81.

Lamba, S., \& Mace, R. (2011). Demography and ecology drive variation in cooperation across human populations. Proceedings of the National Academy of Sciences, 108, $14426-14430$.

LeBar, F. M. (Ed.). (1972). Ethnic Groups of Insular Southeast Asia (Vol. 1: Indonesia, Andaman Islands, and Madagascar). New Haven, CT: HRAF Press.

LeBar, F. M. (Ed.). (1975). Ethnic Groups of Insular Southeast Asia (Vol. 2: Philippines and Formosa). New Haven, CT: HRAF Press.

Levinson, D., \& O'Leary, T. (Eds.). (1996). Encyclopedia of World Cultures (Vol. 5: East and Southeast Asia). New York: MacMillan Reference USA.

Levinson, D., \& O'Leary, T. (Eds.). (1996). Encyclopedia of World Cultures (Vol. 2: Oceania). New York: MacMillan Reference USA.

Levinson, D., \& O'Leary, T. (Eds.). (2002). Encyclopedia of World Cultures (Vol. Supplement). New York: MacMillan Reference USA.

Mace, R., \& Jordan, F. M. (2011). Macro-evolutionary studies of cultural diversity: A review of empirical studies of cultural transmission and cultural adaptation. Philosophical Transactions of the Royal Societ B: Biological Sciences, 366, 402-411.

Mace, R., \& Pagel, M. (1994). The comparative method in anthropology. Current Anthropology, 35, 549-564.

Maine, H. (1876). Village communities in the East and West. London: John Murray.

Marck, J. (2010). Proto-Polynesian *kainanga. In J. Bowden, N. Himmelmann, M. Ross, \& A. Pawley (Eds.), A journey through Austronesian and Papuan linguistics and cultural space: papers in honour of Andrew K. Pawley (pp. 607-620). Canberra: Pacific Linguistics.

McCoy, M. D., Mills, P. R., Lundbald, S., Rieth, T., Kahn, J. G., \& Gard, R. (2011). A cost surface model of volcanic glass quarrying and exchange in Hawai'i. Journal of Archaeological Science, 38, 2547-2560.

Morgan, L. H. (1877). Ancient society. London: MacMillan \& Company.

Morris, D. W., Lundberg, P., \& Ripa, J. (2001). Hamilton's rule confronts ideal free habitat selection. Proceedings of the Royal Society B, 268, 921-924.

Netting, R. M. (1993). Smallholders, householders. Stanford, CA: Stanford University Press.

Nunn, C. L. (2011). The comparative approach in evolutionary anthropology and biology. Chicago: University of Chicago Press.

O'Brien, M. J., \& Laland, K. N. (2012). Genes, culture, and agriculture: an example of human niche construction. Current Anthropology, 53, 434-470.

Oota, H., Settheetham-Ishida, W., Tiwawech, D., Ishida, T., \& Stoneking, M. (2001). Human mtDNA and Y-chromosome variation is correlated with matrilocal versus patrilocal residence. Nature Genetics, 29, 20-21.
Orme, D., Freckleton, R., Petzoldt, T., Fritz, S., \& Isaac, N. (2011). Caper: comparative analysis of phylogenetics and evolution in R R Package Version 0.4. from. http:// CRAN.R-project.org/package $=$ caper

Pagel, M. (1994). Detecting correlated evolution on phylogenies: a general method for the comparative analysis of discrete characters. Proceedings of the Royal Society London B, 255, 37-45.

Pagel, M. (1999). The maximum likelihood approach to reconstructing ancestral character states of discrete characters on phylogenies. Systematic Biology, 48, 612-622.

Pagel, M., \& Meade, A. (2006). Bayesian analysis of correlated evolution of discrete characters by reversible-jump Markov chain Monte Carlo. The American Naturalist $167,808-825$

Pagel, M., Meade, A., \& Barker, D. (2004). Bayesian estimation of ancestral character states on phylogenies. Systematic Biology, 53, 673-684.

Pawley, A. (2005). The meaning(s) of Proto Oceanic *panua. In C. Gross, H. Lyons, \& D. Counts (Eds.), A polymath anthropologist: essays in honour of Ann Chowning (pp. 211-223). Auckland: University of Auckland.

Roscoe, P. (1996). Tongareva. In D. Levinson, \& T. O'Leary (Eds.), Encyclopedia of World Cultures. Oceania, Vol. 2. (pp. 339-342). New York: Macmillan Reference USA.

Ross, M., Pawley, A., \& Osmond, M. (Eds.). (1998). The lexicon of Proto Oceanic: the culture and environment of ancestral Oceanic society. Canberra: Australian National University.

Sahlins, M. D. (1958). Social stratification in Polynesia. Seattle: University of Washington Press.

Sanderson, S. K. (2007). Evolutionism and its critics: deconstructing and reconstructing and evolutionary interpretation of human society. Boulder, CO: Paradigm Publishers.

Scheffler, H. (1996). Choiseul Island. In D. Levinson, \& T. O'Leary (Eds.), Encyclopedia of World Cultures. Oceania, Vol. 2. (pp. 37-40). New York: Macmillan Reference USA.

Shennan, S. (2011). Property and wealth inequality as cultural niche construction. Philosophical Transactions of the Royal Society, B: Biological Sciences, 366, 918-926.

Smith, E. A. (1988). Risk and uncertainty in the "original affluent society": evolutionary ecology of resource sharing and land tenure. In T. Ingold, D. Riches, \& J. Woodburn (Eds.), Hunters and Gatherers: History, Evolution, and Social Change (pp. 222-252). Oxford: Berg.

Tehrani, J. J. (2013). The phylogeny of Little Red Riding Hood. PLoS One, 8(11), e78871.

Utrecht, E. (1969). Land reform in Indonesia. Bulletin of Indonesia Economic Studies, $5,71-88$.

Voland, E., \& Dunbar, R. I. M. (1995). Resource competition and reproduction: the relationship between economic and parental strategies in the Krummhörn population (1720-1874). Human Nature, 6, 33-49.

Walker, R. S., \& Hamilton, M. J. (2011). Social complexity and linguistic diversity in the Austronesian and Bantu population expansions. Proceedings of the Royal Society B, 278, 1399-1404.

Wilkins, J. F., \& Marlowe, F. W. (2006). Sex-biased migration in humans: what should we expect from genetic data? BioEssays, 28, 290-300.

Yang, Z., \& Ranalla, B. (1997). Bayesian phylogenetic inference using DNA sequences: a Markov chain Monte Carlo method. Molecular Biology and Evolution, 14 717-724. 